\title{
Perancangan Sistem Delivery Fastfood Berbasis Web Dengan Metode Gis (Geographic Information System)
}

\author{
Surya Hendra Putra SE, M.Kom \\ Politeknik Ganesha Medan \\ Jl. Veteran No. 194 Pasar VI Manunggal \\ Medan, Sumatera Utara \\ surya_hendra_putra@yahoo.com
}

\author{
Yulia Endah Sari \\ Politeknik Ganesha Medan \\ Jl. Veteran No.194 Pasar VI Manunggal \\ Medan, Sumatera Utara \\ yuliaendah30@gmail.com
}

\begin{abstract}
Abstrak - Layanan pemesanan makanan dengan sistem delivery order saat ini semakin banyak digunakan pada rumah makan-rumah makan yang menyediakan jenis makanan fastfood. Pemesanan makanan maupun minuman fastfood selama ini banyak yang masih menggunakan cara manual dengan menggunakan media telepon, dimana konsumen akan bertanya menu apa saja yang tersedia serta harganya, sehingga konsumen dapat memesan makanan yang diinginkannya. Selain itu, kesulitan yang lain adalah pada saat pengiriman barang, dimana alamat pengiriman yang diberikan konsumen pada saat melakukan pemesanan sering tidak lengkap dan jelas dan mempersulit bagian pengirim pesanan. Sistem ini diharapkan dapat mempermudah rumah makan dalam menyajikan informasi dan promosi rumah makan seperti menu makanan dan minuman yang dapat dipesan serta mempermudah masyarakat dalam melakukan pemesanan makanan dan minuman secara online tanpa harus datang langsung kerumah makan dikarenakan makanan dan minuman yang dipesan langsung diantar kerumah dengan sistem delivery. Sistem ini juga dilengkapi dengan fasilitas GIS (Geographic Information System), sehingga pengirim/pengantar dapat mengetahui lokasi atau alamat dimana makanan akan diantar.
\end{abstract}

Kata Kunci - Perancangan, Delivery order, Fastfood, GIS.

\section{PENDAHULUAN}

Layanan pemesanan makanan dengan sistem delivery order saat ini semakin banyak digunakan pada rumah makan-rumah makan yang menyediakan jenis makanan fastfood. Pemesanan makanan maupun minuman fastfood selama ini banyak yang masih menggunakan cara manual dengan menggunakan media telepon, dimana konsumen akan bertanya menu apa saja yang tersedia serta harganya, sehingga konsumen dapat memesan makanan yang diinginkannya. Selain itu, kesulitan yang lain adalah pada saat pengiriman barang, dimana alamat pengiriman yang diberikan konsumen pada saat melakukan pemesanan sering tidak lengkap dan jelas dan mempersulit bagian pengirim pesanan. Berdasarkan permasalahan yang telah penulis paparkan dan penelitian yang telah dilakukan sebelumnya, maka penulis membuat sistem delivery fastfood berbasis web dengan metode GIS. pengirim/pengantar dapat mengetahui 
lokasi atau alamat dimana makanan akan diantar.

\section{TINJAUAN PUSTAKA}

\subsection{Delivery Order}

Pengiriman pesanan (delivery order) merupakan salah satu layanan pesan antar barang yang sangat popular. Selain mempermudah konsumen dalam mendapat barang, layanan ini juga membantu meningkatkan penjualan bagi perusahaan tersebut, karena kebanyakan masyarakat modern cenderung lebih suka memesan barang untuk diantar ke rumah daripada membeli barang secara langsung.

\subsection{Food Delivery Order}

Food delivery order atau sering disebut dengan FDO adalah suatu jasa antar makanan yang akan memanjakan dan memudahkan penjelajah kuliner untuk berwisata kuliner di rumah atau bagi orang-orang yang super sibuk dan tidak ada waktu untuk datang ke rumah makan. FDO banyak digunakan oleh rumah makan cepat saji (fastfood) untuk meningkatkan penjualan dan memudahkan pelanggan karena hanya dengan menghubungi via sms atau telephone langsung ke layanan jasa FDO dan menunggu beberapa menit maka makanan pun tiba di rumah tanpa harus datang sendiri kewarung untuk memesan, mengantri dan menunggu pesanan yang membosankan.

\subsection{Hypertext Tansfer Protocol( HTTP)}

HTTP adalah fasilitas yang terdapat di server yang bertugas menangani permintaan-permintaan (request) dari browser untuk mengambil dokumendokumen web. HTTP bekerja di atas TCP (Transmission Control Protocol) yang menjamin sampainya data ditujukan dalam urutan yang benar. Pada awalnya HTTP tidak memiliki session yang menjaga hubungan antara client dan server secara konsisten. Dengan kata lain setiap halaman web yang dikirim, terkoneksi antara server akan terputus. Hal ini yang menyebabakan HTTP disebut sebagai protokol. Sifat HTTP ini sangat tidak menguntungkan untuk menstransfer beberapa file, sebab sebuah halaman web biasanya memiliki beberapa file gambar. Dikarenakan kelemahannya itu maka dibuat standar baru dari HTTP, yaitu HTTP/1.1 (didefinisikan oleh RFC 2068).

\subsection{Personal Home Page Hypertext Preprocessor ( PHP )}

PHP merupakan suatu bahasa pemograman sisi server yang dapat anda gunakan untuk membuat halaman web dinamis. Contoh bahasa yang lain adalah Microsoft Active server page (ASP) dan Java Server Page (JPS). Dalam Suatu halaman HTML Anda dapat menanamkan kode PHP yang akan dieksekusi setiap kali halaman tersebut dikunjungi. PHP memiliki banyak fitur yang mempermudah perancangan dan pemograman Web, sehingga memiliki popularitas yang tinggi.

\subsection{Sistem Informasi Geografis}

Sistem informasi geografis adalah kumpulan yang terorganisir dari perangkat keras komputer, perangkat lunak, datd geografis dan personil yang dirancang secara efisien untuk memperoleh, menyimpan, mengupdate, memanipulasi, menganalisis dan menampilkan semua bentuk informasi yang bereferensi goegrafis (Prahasta, 2014 : 101).

\subsection{Peta}

Peta adalah gambaran permukaan bumi pada bidang datar dengan skala tertentu melalui suatu sistem proyeksi. Peta bisa disajikan dalam berbagai cara yang berbeda, mulai dari peta konvensional yang tercetak hingga peta digital yang tampil di layar komputer.

\subsection{Google Maps API}

Google menyediakan layanan API (Application Programming Interface) memungkinkan aplikasi client untuk melihat, menyimpan dan memperbarui data peta dalam bentuk Data API Google feed dengan menggunakan model data fitur (letak, garis dan bentuk) dalam peta. 
Aplikasi ini diberi nama Google Maps API (GMaps API). Peta yang ditampilkan diambil dari layanan Google Maps.

\subsection{Basis Data (Database)}

Basis Data terdiri atas dua kata, yaitu Basis dan Data. Basis kurang lebih dapat diartikan sebagai markas atau gudang, tempat bersarang atau berkumpul. Sedangkan data adalah representasi fakta dunia nyata yang mewakili suatu objek seperti manusia (pegawai, siswa, pembeli, pelanggan), barang, hewan, peristiwa, konsep, keadaan, dan sebagainya, yang diwujudkan dalam bentuk angka, huruf, simbol, teks, gambar, bunyi, atau kombinasinya (Fathansyah, 2015 : 2).

\subsubsection{DBMS (Database Management System)}

\begin{tabular}{|c|c|c|}
\hline & $\begin{array}{l}\text { Database } \\
\text { sistem }\end{array}$ & $\begin{array}{c}\text { Management } \\
\text { software }\end{array}$ \\
\hline $\mathrm{o}_{0}$ & gkinka & pengguna \\
\hline
\end{tabular}
mendefinisikan, membuat, memelihara, dan kontrol akses ke database. DBMS adalah software yang berinteraksi dengan program aplikasi dan pengguna database.

\subsubsection{Entity Relationship Diagram (ERD) \\ Entity Relationship Diagram} (ERD) digunakan untuk menggambarkan hubungan antara penyimpangan atau data storange yang dapat pada DFD,ERD menggunakan sejumlah notasi untuk menggambarkan struktur dan hubungan antar data.

\subsubsection{MySQL Server 5.0}

MySQL adalah suatu sistem manajemen basis data relasional (RDBMS-Relational Database Management System) yang mampu berkerja dengan cepat, kokoh dan mudah digunakan (Pratama, 2010 : 10).

\subsubsection{Data Flow Diagram (DFD)}

Data Flow Diagram (DFD) adalah suatu diagram yang menggunakan notasi-notasi untuk menggambarkan arus dari data sistem, yang penggunaanya sangat membantu untuk memahami sistem secara logika, terstruktur dan jelas (Sunyoto, 2014 : 129).

\subsubsection{Flow Chart ( FC ) \\ Flowchart}

merupakan

penggambaran secara grafik dari langkahlangkah dan urutan prosedur suatu program (Sunyoto, 2014 : 129)

\section{METODE PENELITIAN}

\subsection{Metode Analisi Data}

Pada tahap metode analisa, peneliti melakukan analisa kasus dengan membandingkan dan mencari berita-berita terkait serta mencari literature penelitianpenelitian yang pernah dilakukan sebelumnya tentang perancangan sistem delivery fastfood berbasis web dengan metode GIS menggunakan metode analisa kualitatif deskriptifdengan terlibat langsung dalam proses sistem.

\section{ANALISA DAN PEMBAHASAN}

\subsection{Analisa Sistem yang sedang Berjalan}

Pada sistem yang berjalan, semua pengolahan data masih dilakukan secara manual tidak menggunakan aplikasi atau pun form khusus, untuk menunjukan menu yang tersedia pada Warung Aja digunakan daftar menu yang dicetak full color yang didalamnya berisikan gambar menu masakan, minuman dan harga pada masing-masing menu, termasuk juga didalamnya info paket makanan yang tersedia.

Order makan yang dilakukan oleh pelanggan hanya akan ditanya dalam buku notes kecil yang kemudian akan di informasikan kepada bagian dapur untuk dilakukan proses masak. Bila seluruh pesanan yang di order oleh konsumen telah diantar ke meja pelanggan catatan notes tersebut diserahkan kebagian kasir untuk kemudian dicatat ulang pada form pesanan yang tersedia dimeja kasir.

Proses pembayaran dapat dilakukan dengan dua cara, yaitu dengan memanggil pelayan untuk meminta bon tagihan atau langsung mendatangi meja kasir untuk melakukan transaksi 
pembayaran, pengitungan seluruh tagihan yang sudah di pesan atau beli dilakukan oleh mesin cash register.

\subsection{DFD (Data Flow Diagram)}

Berikut adalah DFD (Data Flow Diagram) pada sistem yang sedang berjalan,dimana proses pemesanan hingga ke proses pembayaran dilakukan secara manual.

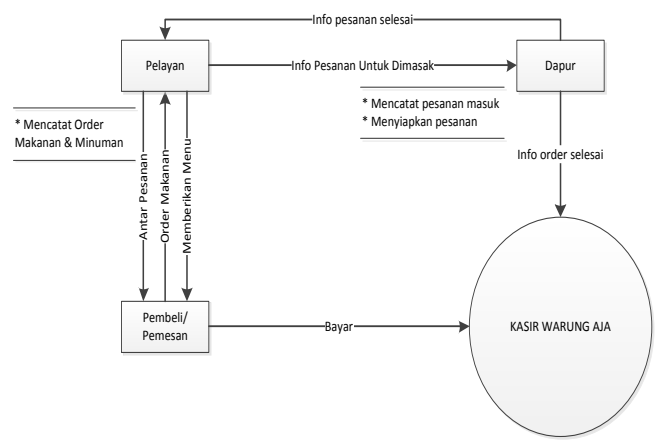

Gambar 4.1 DFD Sistem yang berjalan

\subsection{Flowchart}

Berikut adalah flowchart dari sistem informasi delivery fastfood berbasis web dengan metode GIS (Geographic Information System).

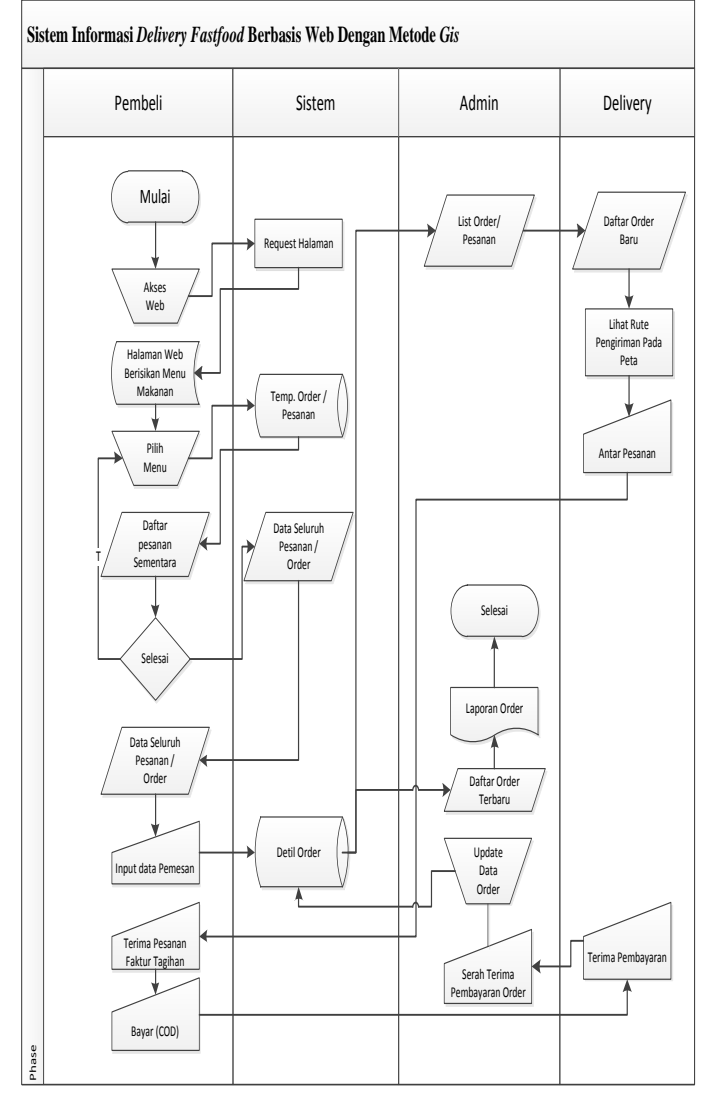

Gambar 4.2 Flowchart Sistem Delivery Fastfood

4.4 Implementasi Sistem dan Pembahasan

Pada proses implementasi interface sistem informasi delivery FastFood dibagi kedalam 2 (dua) bagian besar yaitu bagian frontend dan backend.

1. Beranda

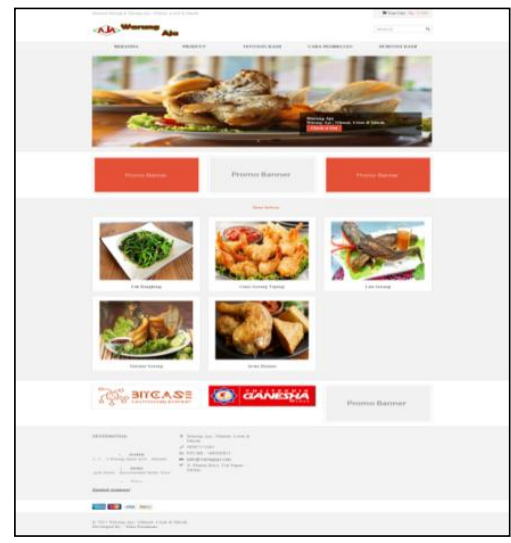

Gambar 4.3 Tampilan Beranda

2. Cara Pembelian 


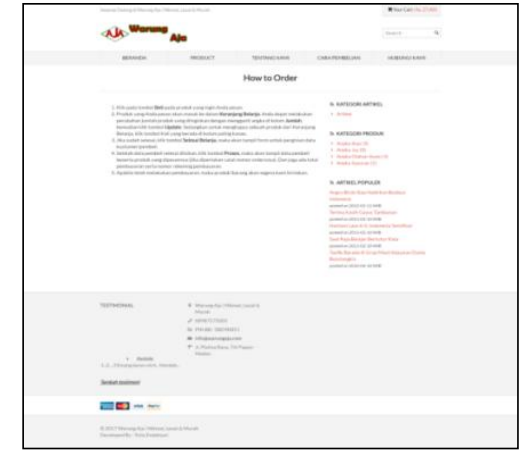

Gambar 4.4 Tampilan cara pembelian

3. Halaman Data Order

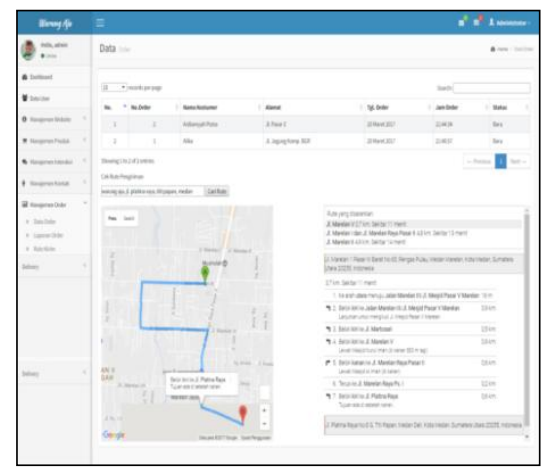

Gambar 4.5 Tampilan data order

4.5 Coding untuk menampilkan GIS

(Geographic Information System)

function initMap()\{

console.log('called')

var myOptions $=\{$

zoom: 15,

scaleControl: true,

center: new

google.maps.LatLng(3.689513,

98.661001)

mapTypeld:

google.maps.MapTypeld.ROADMAP

\} var map $=$ new

google.maps.Map(document.getElementB yld("map"),

myOptions);

var marker1 = new google. maps. Marker(\{

position : new

google.maps.LatLng(3.689513,

98.661001)

title : 'lokasi',

map : map,

draggable : true

\});

var input $=$

document.getElementByld('autocomplete _alamat');

var autocomplete $=$ new google.maps.places.Autocomplete(input);

autocomplete.bindTo('bounds', map);

google.maps.event.addListener(autocomp lete, 'place_changed', function() \{

var place $=$ autocomplete.getPlace();

if (!place.geometry) \{

return;

\}

if (place.geometry.viewport) \{ map.fitBounds(place.geometry.viewport);

\} else \{

map.setCenter(place.geometry.location);

map.setZoom(18);

\}

marker1.setPosition(place.geome try.location)

updateMarkerPosition(place.geo

metry.location) 
\});

\section{//updateMarkerPosition(latLng);}

google.maps.event.addListener(marker1, 'drag', function() \{

updateMarkerPosition(marker1.getPositio

$\mathrm{n}())$;

\});

console.log('end called')

\}//end initMap

"http://maps.googleapis.com/maps/api/js? key=AIzaSyBYJrvtQD4JvsYf5HbKplYaz 0NmZrOZ7XE\&callback=initMap\&librari es $=$ places" $\rangle\langle/$ script $\rangle$

\section{KESIMPULAN DAN SARAN}

\subsection{Kesimpulan}

Berikut adalah kesimpulan dari hasil perancangan sistem informasi delivery fastfood, diantaranya adalah :

1. Sistem delivery fastfood akan menampilkan informasi menu makanan dan minuman berbasis web yang dapat diakses secara online.

2. Dengan pemanfaatan internet proses pengiriman makanan dapat menjadi lebih mudah, terutama dalam mencari lokasi pengantaran karena lokasi dapat di tampilkan di dalam bentuk peta digital sehingga lebih akurat.

3. Fasilitas peta digital dari sistem yan telah dibangun dapat membantu dalam proses delivery / pengiriman pesanan kepada konsumen, dimana lokasi pengiriman dan rute pengiriman akan ditampilkan ke peta digital. Peta digital yang diakses menggunakan peta googlemap dan harus terkoneksi dengan internet.
5.2 Berikut adalah saran-saran yang dapat dilakukan untuk pengembangan aplikasi ini dikemudian hari, diantaranya adalah :

1. Sistem COD (Cash On Delivery) masih memiliki kelemahan, karena ada kemungkin pemesanan yang dilakukan adalah merupakan pemesan fiktif, sehingga menimbulkan kerugian dipihak pengelola.

2. Sebaiknya dibangun aplikasi delivery yang dapat khusus dipergunakan pada perangkat smartphone.

3. Perlu ditambahkan modul chatting sehingga pengunjung yang ingin memesan makanan dapat berkomunikasi secara langsung dengan pengelola.

\section{REFERENSI}

1) Eddy Prahasta, Sistem Informasi Geografis Konsep-konsep Dasar (Perspektif Geodesi \& Geomatika), Bandung, 2014

2) Sunyoto S.H, S.E, M.M., DRS. Danang, Sistem Informasi Manajemen Perspektif Organisasi, CAPS, Yogyakarta, 2014

3) Fathansyah, Perancangan Database engine MYSQL, Yogyakarta, 2015

4) Pratama Antonius Nugraha Widhi, Membangun Aplikasi Php,MediaKita, Jakarta Selatan, 2010

5) Rifani,(2015) Sistem Informasi Pemesanan Makanan Berbasis Web di Deneira Catering Lembang, 